\title{
Morfologia e duração dos ínstares larvais de Chrysomya putoria (Wiedemann) (Diptera, Calliphoridae), em laboratório
}

\author{
Marcio Sacramento de Oliveira ${ }^{1,3}$, Rubens Pinto de Mello² \& Margareth Maria de Carvalho Queiroz ${ }^{3}$
}

\begin{abstract}
'Coordenação de Vigilância Ambiental em Saúde - SESDEC/RJ. Rua México, 128 - 20031-142 Rio de Janeiro-RJ, Brasil. marcio.sacramento@saude.rj.gov.br ${ }^{2}$ Depto. Entomologia - IOC/FIOCRUZ. Av. Brasil, 4365 - Caixa Postal 926 - 21045-900 Rio de Janeiro-RJ, Brasil. rmello@ioc.fiocruz.br ${ }^{3}$ Depto. Biologia - IOC/FIOCRUZ. Av. Brasil, 4365 - Caixa Postal 926 - 21045-900 Rio de Janeiro-RJ, Brasil. mmcqueiroz@ioc.fiocruz.br
\end{abstract}

\begin{abstract}
Morphology and duration of larval instars of Chrysomya putoria (Wiedemann) (Diptera, Calliphoridae), in laboratory. The objective of this work was to describe the morphology and the developmental time of Chrysomya putoria larvae, a fly of public health and forensic importance. The samples were collected at $2 \mathrm{hr}$ intervals, during the first $56 \mathrm{hr}$ and at $12 \mathrm{hr}$ intervals thereafter, until all mature larvae had abandoned the diet. The total developmental time for Chrysomya putoria larvae at $27{ }^{\circ} \mathrm{C}$ was $92 \mathrm{hr}$, with a mean length of $13.42 \mathrm{~mm}$. The larvae presented unique morphological characteristics which differentiated them from other exotic and autochthonous species found in Brazil. The cephalopharyngeal skeleton of the third instar larvae is robust and sclerotized; the mouth hook is completely pigmented and curved; the posterior end is wider than the anterior, being slightly pointed. The accessory oral sclerit is absent and the dorsal and ventral horns have areas with less pigmentation. It is possible to visualize an area with no pigmentation adjacent to the horns, outstanding in size near the ventral corn with a well delimited medial incision. The anterior spiracles presented 10 to 11 ramifications, open peritrema and the presence of a spiracular bud from the second instar on.
\end{abstract}

KEYWORDS. Blowfly; forensic entomology; larval morphology.

RESUMO. Morfologia e duração dos ínstares larvais de Chrysomya putoria (Wiedemann) (Diptera, Calliphoridae), em laboratório. Este trabalho visou descrever a morfologia e o tempo de desenvolvimento das larvas de Chrysomya putoria, um importante díptero para saúde pública e medicina legal. As amostras foram coletadas a cada duas horas e, a partir da $56^{a}$ hora, as coletas foram realizadas com intervalos de 12 horas até o abandono das larvas maduras do meio de criação. As larvas de C. putoria apresentaram um tempo total de desenvolvimento de 92 horas quando mantidas a $27^{\circ} \mathrm{C}$ com comprimento médio de $13,42 \mathrm{~mm}$ e características morfológicas peculiares que as diferenciam das outras espécies exóticas e autóctones do Brasil. O esqueleto cefalofaringeano das larvas de terceiro ínstar é robusto e esclerotizado; o gancho labial é completamente pigmentado e curvo, a parte posterior é mais larga que a anterior, mostrando-se levemente pontiagudo. Estas larvas não possuem esclerito oral acessório e o corno dorsal e o ventral apresentam áreas menos pigmentadas. Nota-se uma região não pigmentada em continuação aos cornos, destacando-se no tamanho na região do corno ventral com uma incisão média bem demarcada. Apresentam de 10 a 11 ramificações no espiráculo anterior, peritrema incompleto e presença do botão espiracular, a partir do segundo ínstar.

PALAVRAS-CHAVE. Entomologia forense; morfologia de larvas; mosca varejeira.

Os dípteros da família Calliphoridae são de grande importância médico sanitária devido ao fato dos adultos de muitas espécies serem endófilas, podendo freqüentar alimentos de consumo humano após abandonarem ambientes contaminados (Mariluis 1999) e as formas larvares atuarem como parasitas, produzindo miíases obrigatórias ou facultativas. Uma espécie, Chrysomya putoria (Wiedemann, 1818), desperta interesse por se tratar de um potencial vetor mecânico de polivírus tipo I e III, vírus Coxsackie, Shilella sp., Salmonella sp., Escherichia coli e Giardia lamblia, além de outros patógenos entéricos, e também atuam como agentes irritantes e espoliantes (Greenberg 1971, 1973 e Furlanetto et al. 1984). Podem invadir tecidos necrosados de vertebrados, pois suas larvas podem produzir miíases secundárias (Zumpt 1965). Além disso, as larvas do gênero Chrysomya RobineauDesvoidy (1830) atuam ativamente no processo de degradação de carcaças, sendo, portanto de utilidade na entomologia forense. Visando ampliar o conhecimento da biologia desses dípteros para saúde pública e medicina legal, este trabalho teve como objetivo ampliar o conhecimento sobre a biologia das larvas de C. putoria com ênfase nos aspectos morfológicos e tempo de desenvolvimento larval.

\section{MATERIALE MÉTODOS}

Foram utilizadas 1200 larvas L1, recém eclodidas (neolarvas), provenientes de adultos mantidos em laboratório, divididas igualmente em três recipientes contendo cada $400 \mathrm{~g}$ de carne bovina moída em início de decomposição e mantidas em câmara climatizada regulada a $27 \pm 1{ }^{\circ} \mathrm{C}, 60 \pm 10 \%$ U.R. e 14 horas de fotofase. Uma amostra de 10 neolarvas, computadas como de primeiro ínstar (zero hora), foram sacrificadas em água à temperatura aproximada de $60^{\circ} \mathrm{C}$, clarificadas, diafanizadas e conservadas em lactofenol de Amann. Posteriormente, a cada duas horas foi coletada uma amostra de 10 larvas/repetição; a partir da $56^{\underline{a}}$ hora, as coletas foram realizadas com intervalos de 12 horas, até o abandono das larvas de final de terceiro ínstar do meio de criação (Tabela II). 
Para realização da análise das fases de desenvolvimento e dos desenhos, as larvas foram colocadas entre lâmina escavada e lamínula contendo lactofenol; o esqueleto cefalofaringeano, bem como o primeiro e o último segmento das larvas foram destacados, a fim de facilitar a observação da sua estrutura e dos espiráculos. As observações foram realizadas através de microscópio-esteroscópico ZEISS ${ }^{\circledR}$ STEMI SV6 e microscópio óptico ZEISS ${ }^{\circledR}$, os desenhos foram efetuados com câmara-clara acoplada e objetiva milimetrada.

A morfometria foi baseada em 1020 exemplares, sendo 267 do primeiro ínstar; 205 do segundo e 548 do terceiro. As terminologias utilizadas para descrição dos ínstares larvais de C. putoria seguem as de Lopes (1943 e 1982), McAlpine et al. (1981) e Queiroz et al. (1997).

\section{RESULTADOS}

Descrição das larvas de primeiro ínstar de Chrysomya putoria. O intervalo de tempo deste ínstar compreendeu de zero a 12 horas (Tabela I), onde as larvas apresentavam um comprimento médio de 2,61 $\pm 0,69 \mathrm{~mm}$; corpo composto por 12 segmentos separados por grupos de fileiras de espinhos que variavam em formato, tamanho e posição, localizados nos limites entre os segmentos (Fig. 1).

Pseudocéfalo largo, membranoso e com estreitamento próximo aos palpos e antenas; presença de cristas orais na cavidade pré-oral (Fig. 3); palpos e antenas conspícuos (Fig. 2); primeiro segmento torácico rodeado por grupos de espinhos que variavam em forma e tamanho, posicionados lateralmente acima das cristas orais (Fig. 3); dentes suprabucais presentes e esqueleto cefalofaringeano pouco esclerotizado em relação aos demais ínstares (Fig. 2).

Maxila formada por um par de peças simétricas articuladas na base, largas e esclerotizadas; mandíbula menor que a maxila e formada por um par de peças simétricas, largas, alongadas e menos esclerotizadas; ambas eram ligeiramente curvas com ápices pontiagudos; esclerito dental pouco individualizado em relação à maxila (Figs. 2-3) .

Esclerito hipostomal soldado ao faringeal; o esclerito hipofaringeal apresentou-se como o mais desenvolvido da região intermediária com prolongamento ventral que correspondeu à trave mediana, abaixo da qual encontrava-se o duto da glândula salivar. Visualizada ventralmente apresentava a forma de $\mathbf{H}$ (Fig. 3).

Esclerito infrafaringeal pouco visível unido ao ramo ventral do esclerito faringeal, onde dava lugar à formação dos canalículos da face ventral da luz faringeana.

Esclerito faringeal esclerotizado, apresentando zonas de maior ou menor condensação de pigmentos de escleroproteina; faringe e arco clipeal completos. Corno dorsal pouco maior que o ventral, apresentando margens externas delineadas por linhas paralelas pouco pigmentadas (Figs. 2-3).

Presença no último segmento larval de um par de espiráculos com apenas uma abertura espiracular, que caracteriza o primeiro ínstar (Figs. 1, 4 e 5), um par de tubérculos dorsal interno, um par dorsal mediano, um par dorsal externo, um par ventral mediano e um par ventral externo (Fig. 4).

Transição de primeiro para segundo ínstar (farato). Nesta fase, que ocorreu de 12 às 14 horas (Tabela I), as larvas apresentaram comprimento médio de $3,85 \pm 0,15 \mathrm{~mm}$ e a formação, próximo ao final do segundo segmento torácico, do espiráculo anterior (Fig. 6).

$\mathrm{O}$ esqueleto cefalofaringeano manteve basicamente as estruturas características do primeiro ínstar, com o desenvolvimento da maxila (Fig. 6).

Presença no último segmento (extremidade posterior do abdome) do espiráculo posterior funcional da larva de primeiro ínstar e a formação do espiráculo de segundo; este com duas aberturas espiraculares (Fig. 7).

Segundo ínstar. No intervalo de 14 às 24 horas (Tabela I) o comprimento larval médio foi de $5,9 \pm 0,73 \mathrm{~mm}$. Os segmentos das larvas estavam separados por grupos de fileiras de espinhos que variaram em formato, tamanho e posição, constituídos de uma a três pontas; presença do espiráculo anterior, próximo ao final do segundo segmento torácico, com 10 ou 11 ramificações; pseudocéfalo rico em cristas orais finas, retilíneas e ramificadas (Figs. 8 e 10).

Maxilas fortemente esclerotizadas, curvas, ápice pontiagudo e com as mandíbulas incorporadas. Presença do esclerito dental como uma estrutura separada das maxilas, como também a do anel esclerotizado ventral e do esclerito subhipostomal (Fig. 9).

Esclerito hipostomal presente sob a forma de uma barra ligada ao esclerito faringeal e sobre o infra-faringeal que estava unido ao ramo ventral do esclerito faringeal, onde encontramos estrias longitudinais. Depressão ocular pouco esclerotizada ocorrendo entre o esclerito faringeal e o hipostomal. Arco clipeal e esclerito faringeal bastante pigmentados; corno dorsal com extremidade ligeiramente afilada e áreas pouco esclerotizadas; corno ventral com extremidade maior e mais arredondada que o dorsal, sua extremidade final apresentouse maior com áreas fracamente esclerotizadas. Os cornos apresentaram margens externas pouco pigmentadas. A incisão média entre os cornos estava bem demarcada (Figs. 8-9).

Presença no último segmento abdominal das larvas de um par de espiráculos posteriores com duas aberturas cada (característica da larva de segundo ínstar); peritrema incompleto, convexo e bastante pigmentado, com a presença de botão espiracular. Na margem dorsal, desse segmento, encontramos três pares de tubérculos sendo um par dorsal interno, um par dorsal mediano e um par dorsal externo; observamos ventralmente um par de tubérculos ventral externo, um par ventral mediano e um par ventral interno, além de um par de tubérculos anais mais posteriormente. Inúmeras setas e grupos de fileiras de espinhos de diferentes tamanhos e formatos encontravam-se distribuídos por essa região (Figs. 11-12).

Transição de segundo para terceiro ínstar (farato). Nesta fase, entre as 24 e 28 horas (Tabela I), as larvas apresentavam as características do segundo ínstar com a formação do espiráculo 


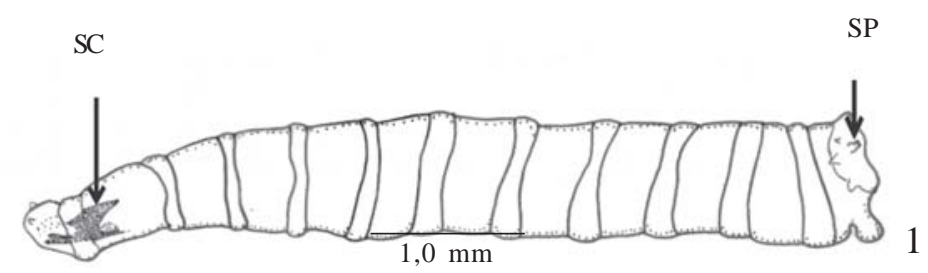

$\mathrm{L}$

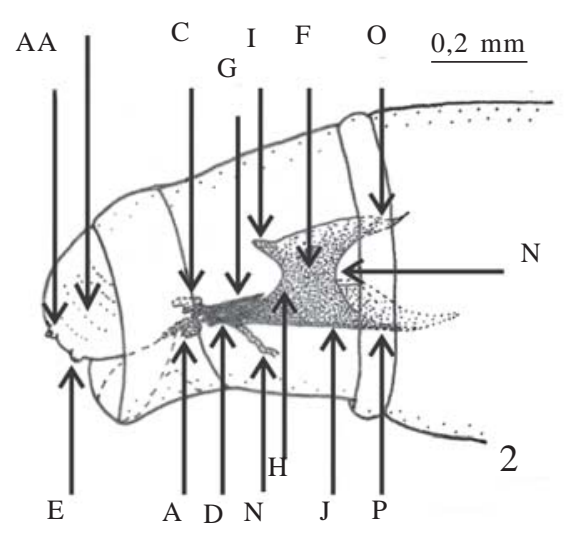

A

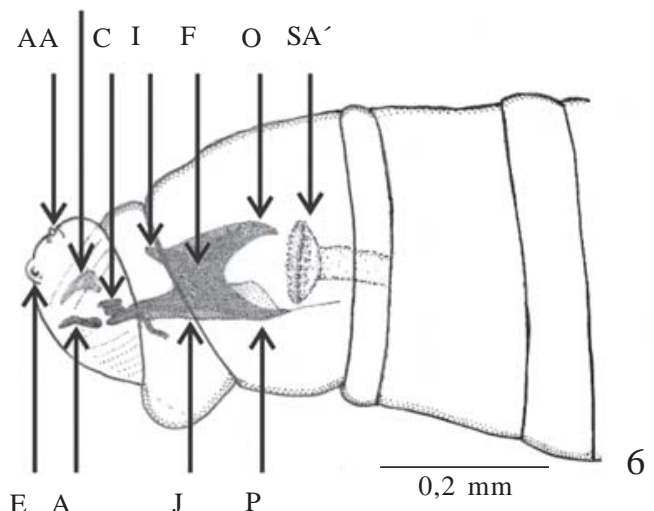

AA

A

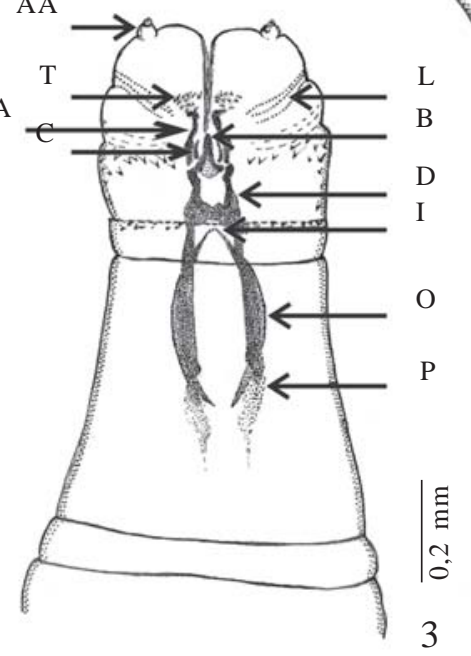

3
DI

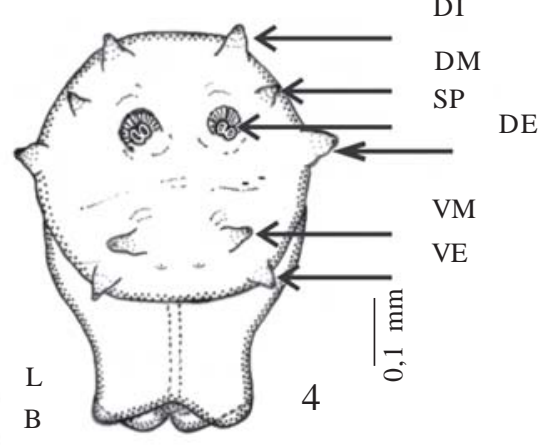

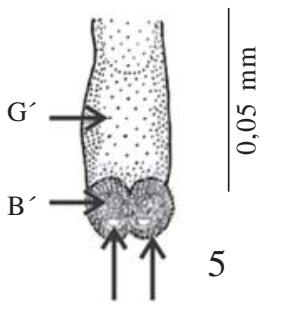

$\mathrm{C}^{\prime} \mathrm{A}^{\prime}$

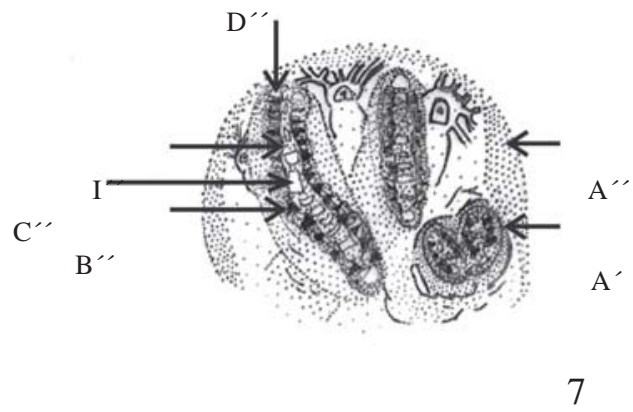

$0,1 \mathrm{~mm}$

Figs. 1-7. 1-5, Larva de primeiro ínstar de Chrysomia putoria (Wiedemann, 1818) com 10 horas. 1- Vista lateral; 2- Vista lateral da extremidade anterior; 3- Vista ventral da extremidade anterior; 4- Vista posterior da extremidade posterior; 5- Espiráculo posterior: 6-7, Larva em transição do primeiro para o segundo ínstar (farata) de Chrysomia putoria (Wiedemann, 1818) com 14 horas. 6- Vista lateral da extremidade anterior; 7Espiráculo posterior. - Legenda: AA- antena; A- maxila (gancho bucal ou esclerito oral); A $^{2}$ - maxila; B- esclerito dental (dentado); C- mandíbula; D- esclerito hipofaringeal (infra hipostomal); E- palpo maxilar; F- esclerito faringeal; G- esclerito hipostomal (barra parastomal ou paraclipeal); H- clípeo; I- arco clipeal; J- esclerito infrafaringeal; L- cristas orais; M- conduto da glândula salivar; N-incisão média; O- corno dorsal; P- corno ventral; T- dentes suprabucais; DI- tubérculo dorsal interno; DM- tubérculo dorsal mediano; DE- tubérculo dorsal externo; VE- tubérculo ventral externo; VM- tubérculo ventral mediano; SA'- espiráculo anterior; SC- esqueleto cefalofaringeal; SP- espiráculo posterior; A'- peritrema; A"peritrema em formação; B'- rima; B"- rima em formação; C'- abertura espiracular; C" abertura espiracular em formação; D"- orifícios espiraculares em formação; G'- câmara espiracular; I"- trabéculas em formação.

anterior de terceiro ínstar, que no decorrer do tempo foi se modificando até atingir a forma definitiva (Fig. 14).

$\mathrm{O}$ esqueleto cefalofaringeano manteve basicamente as estruturas características do segundo ínstar com o desenvolvimento da maxila e dos cornos dorsal e ventral (Fig. 13).

No último segmento larval, observamos a presença do espiráculo posterior funcional da larva de segundo ínstar e a formação do espiráculo de terceiro, este com três aberturas espiraculares (Fig. 15). O comprimento larval médio foi de 7,82 $\pm 0,37 \mathrm{~mm}$.

Terceiro ínstar. No último ínstar, entre $28^{\mathrm{a}} \mathrm{e} 92^{\mathrm{a}}$ hora (Tabela 1), as larvas apresentaram comprimento médio de 13,48 $\pm 1,77$ $\mathrm{mm}$ com início do abandono da dieta às 68 horas. Esqueleto cefalofaringeano totalmente formado. Maxilas curvas, robustas e totalmente esclerotizadas, parte posterior larga afinando em direção a anterior, que se apresentou pontiaguda; as 

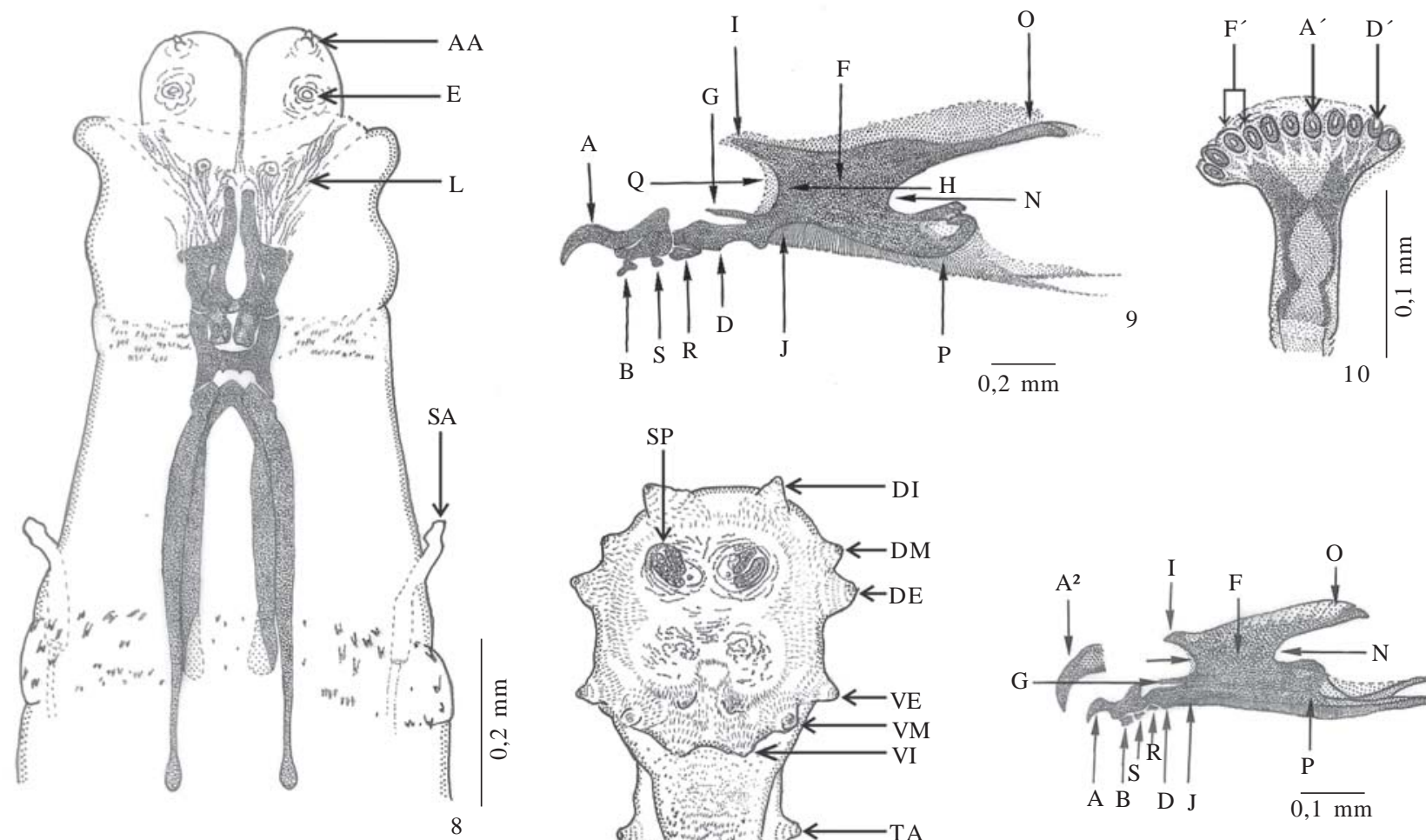

10
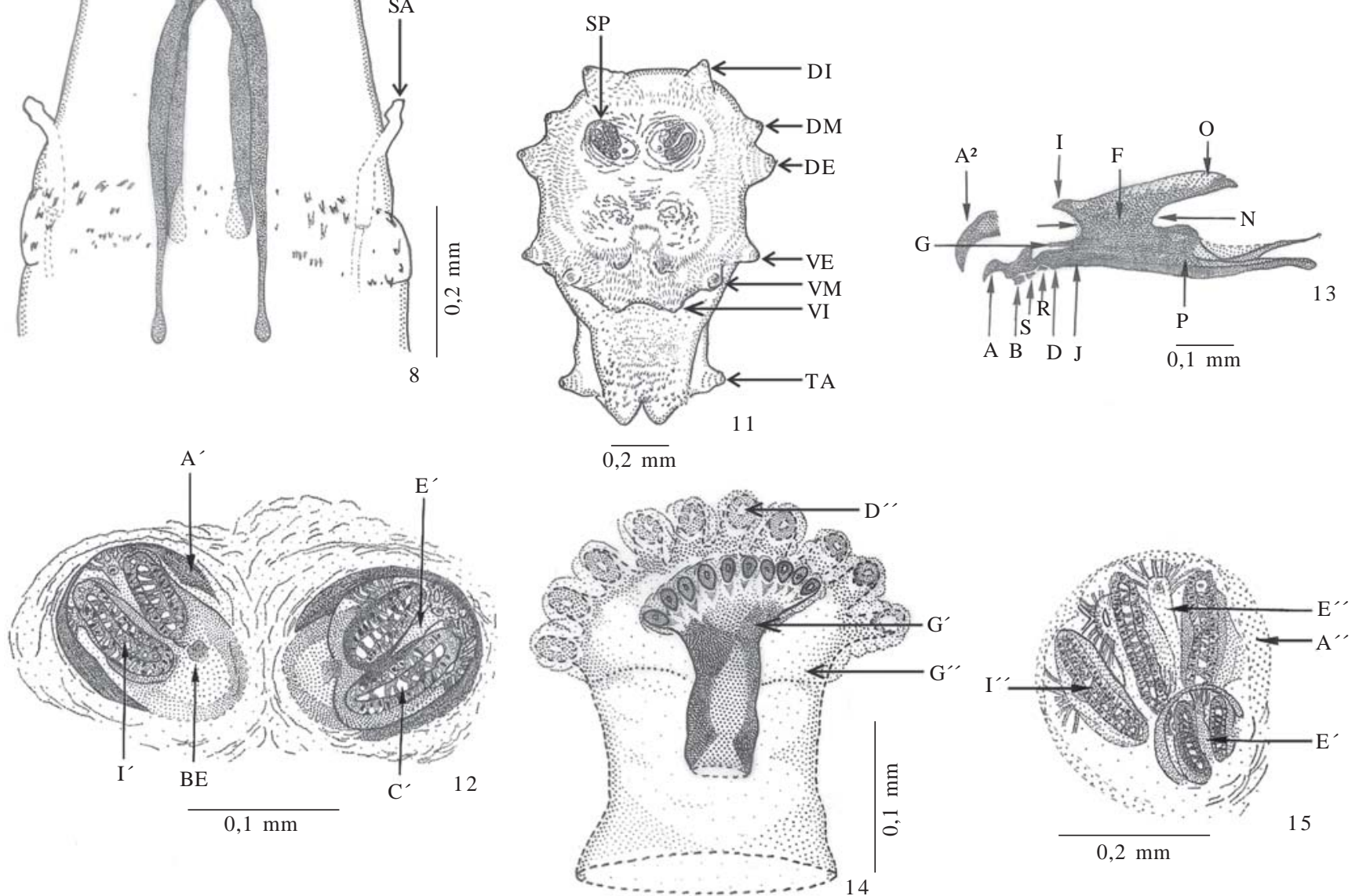

Figs. 8-15. 8-12, Larva de segundo ínstar de Chrysomia putoria (Wiedemann, 1818) com 22 horas. 8- Vista ventral da extremidade anterior; 9Vista lateral do esqueleto cefalofaringeal; 10- Espiráculo anterior; 11- Vista posterior da extremidade posterior; 12- Espiráculo posterior. 13-15, Larva em transição do segundo para o terceiro ínstar (farata) de Chrysomia putoria (Wiedemann, 1818) com 26 horas. 13- Vista lateral do esqueleto cefalofaringeal; 14- Espiráculo anterior; 15- Espiráculo posterior. - Legenda: AA- antena; A- maxila; A²- maxila; B- esclerito dental; Desclerito hipofaringeal; E- palpo maxilar; F- esclerito faringeal; G- esclerito hipostomal; H- clípeo; I- arco clipeal; J- esclerito infrafaringeal; Nincisão média; O- corno dorsal; P- corno ventral; Q- depressão ocular; R- esclerito sub-hipostomal; S- anel quitinoso ventral;T- dentes suprabucais; BE- botão espiracular; DI- tubérculo dorsal interno; DM- tubérculo dorsal mediano; DE- tubérculo dorsal externo; VE- tubérculo ventral externo; VM- tubérculo ventral mediano; VI- tubérculo ventral interno; SA'- espiráculo anterior; SC- esqueleto cefalofaringeal; SP- espiráculo posterior; TA- tubérculo anal; A'- peritrema; A"- peritrema em formação; B'- rima; B"- rima em formação; C'- abertura espiracular; C" abertura espiracular em formação; D'- orifício espiracular; D"- orifício espiracular em formação; E'- placa espiracular; E”- placa espiracular em formação; F'ramificações espiracular; G'- câmara espiracular; G”- câmara espiracular em formação; I'- trabéculas; I"- trabéculas em formação.

mandíbulas encontravam-se incorporadas às maxilas. Esclerito dentado e anel esclerotizado ventral bem constituídos; o esclerito hipostomal e o infra-faringeal permaneceram unidos fortemente ao faringeal onde deram lugar as estrias da face ventral da luz faringeana (Fig. 16).

Esclerito faringeal e arco clipeal bem esclerotizados; corno dorsal e ventral apresentavam áreas menos pigmentadas com uma região não pigmentada em continuação aos cornos, destacando-se no tamanho na região do corno ventral e incisão média bem demarcada (Fig. 16).

Presença próxima ao final do segundo segmento torácico do espiráculo anterior de terceiro ínstar totalmente formado e 
apresentando de 10 a 11 ramificações; no último segmento abdominal, observamos um par de espiráculos posteriores, com três aberturas cada (característica da larva de terceiro ínstar); peritrema incompleto, convexo, bastante pigmentado com estruturas proeminentes entre as aberturas espiraculares e a presença do botão espiracular (Figs. 17 e 18). Na margem dorsal, desse segmento, encontramos três pares de tubérculos sendo um par dorsal interno, um par dorsal mediano e um par dorsal externo; posteriormente, observamos um par de tubérculos ventral externo, um par ventral mediano e um par ventral interno; mais posteriormente um par de tubérculos anais. Foram visualizadas diversas setas distribuídas nessa região e grupos de fileiras de espinhos de diferentes tamanhos e formas (Fig. 17).

\section{DISCUSSÃO}

Dentro da família Calliphoridae, a distinção entre a maioria das formas de terceiro ínstar em nível de gênero, não é difícil. Algumas espécies possuem características bem marcantes que as tornam fáceis de identificar; por outro lado, algumas são tão semelhantes que por uma análise rápida é quase impossível distingui-las. A morfologia das larvas de Chrysomya megacephala (Fabricius, 1794) e C. putoria é um bom exemplo disso, pois apresentam muitas semelhanças, sendo difícil diferenciá-las morfologicamente.

Para Zumpt (1965), a distância entre os dois peritremas posteriores pode ser utilizada para distinguir as larvas de $C$. megacephala de C. putoria, mas Prins (1979), examinando alguns exemplares de C. megacephala e Chrysomya chloropyga (Wiedemann, 1818), averiguou consideráveis diferenças que dificultam a diferenciação morfológica só por essa característica.

As larvas de $C$. putoria seguiram o padrão do período de desenvolvimento observado na grande parte dos dípteros Cyclorrhapha, onde o primeiro ínstar foi o mais curto apresentando um comprimento médio de 2,75 $\mathrm{mm}$ após 14 horas, seguido pelo segundo $(6,42 \mathrm{~mm}$, de 14 a 28 horas $)$ e o terceiro ínstar como o mais longo (13,3 mm, de 28 a 92 horas).

Prins (1982) trabalhando com gênero Chrysomya observou em C. albiceps que a duração do primeiro ínstar larval variava entre a $15^{\mathrm{a}} \mathrm{e} 20^{\mathrm{a}}$ hora, com um comprimento médio de $3 \mathrm{~mm}$ às

Tabela I. Desenvolvimento dos ínstares larvais de Chrysomya putoria (Wiedemann, 1818), representado pelo tamanho (mm), criadas em carne bovina em início de decomposição e mantidas em câmara climatizada regulada a $27 \pm 1^{\circ} \mathrm{C}, 60 \pm 10 \%$ U.R. e fotofase de 14 horas.

\begin{tabular}{lcccc}
\hline \multirow{2}{*}{ InstaresLarvais } & $\begin{array}{c}\text { Duração } \\
\text { (horas) }\end{array}$ & \multicolumn{3}{c}{ Tamanho $(\mathrm{mm})$} \\
\cline { 3 - 5 } & $0-12$ & 2,61 & 0,69 & $1,23-3,92$ \\
\hline Primeiro & $12-14$ & 3,85 & 0,15 & $3,59-4,35$ \\
Farato $\left(11^{\circ} 2^{\circ}\right)$ & $14-24$ & 5,90 & 0,73 & $4,41-7,15$ \\
Segundo & $24-28$ & 7,82 & 0,37 & $7,31-8,60$ \\
Farato $\left(2^{\circ} / 3^{\circ}\right)$ & $28-92$ & 13,48 & 1,77 & $8,67-16,67$ \\
Terceiro & 28 &
\end{tabular}

* DP - Desvio Padrão

** IV 95\% - Intervalo de Variação de 95\%
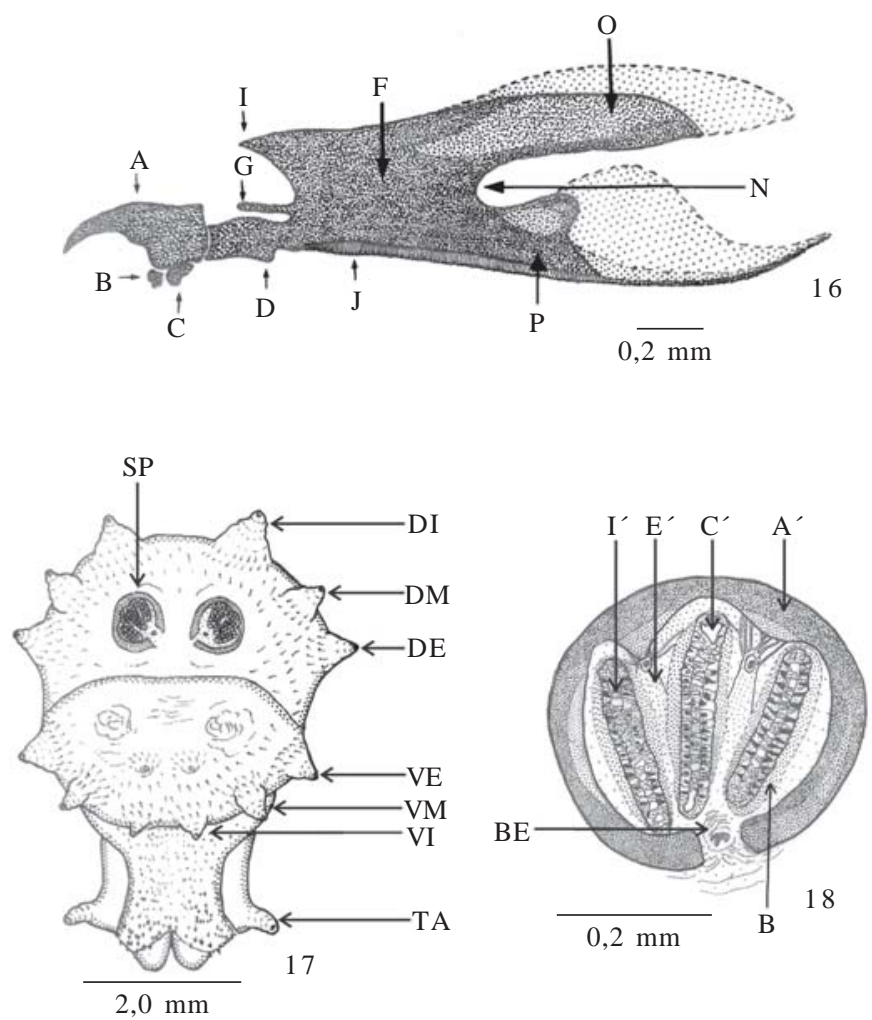

Figs. 16-18. Larva de terceiro instar de Chrysomia putoria (Wiedemann, 1818) com 56 horas. 16- Vista lateral do esqueleto cefalofaringeal; 17Vista posterior da extremidade posterior; 18- Espiráculo posterior. Legenda: A- maxila; B- esclerito dental; D- esclerito hipofaringeal; Fesclerito faringeal; G- esclerito hipostomal; I- arco clipeal; J- esclerito infrafaringeal; N- incisão média; O- corno dorsal; P- corno ventral; Sanel quitinoso ventral; BE- botão espiracular; DI- tubérculo dorsal interno; DM- tubérculo dorsal mediano; DE- tubérculo dorsal externo; VE- tubérculo ventral externo; VM- tubérculo ventral mediano; VItubérculo ventral interno; SP- espiráculo posterior; TA- tubérculo anal; A'- peritrema; B'- rima; C'- abertura espiracular; E'- placa espiracular; I'- trabéculas.

12h, o segundo ínstar ocorreu entre a $26^{\mathrm{a}}$ e $30^{\mathrm{a}}$ hora após a eclosão, com um comprimento de 6-7 mm, o terceiro ínstar variou da $153^{\mathrm{a}}$ a $158^{\mathrm{a}}$ hora em uma temperatura de $25-28^{\circ} \mathrm{C}$. Para C. megacephala Prins (1982) verificou o tempo de duração do primeiro ínstar em $26 \mathrm{~h}$, e durante este período as larvas tinham de 3 a $4 \mathrm{~mm}$. O segundo ínstar durou em torno de $21 \mathrm{~h}$, e as larvas apresentaram normalmente um comprimento de 6

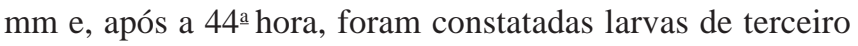
ínstar, que ocorreu da $140^{\mathrm{a}}$ à $148^{\mathrm{a}}$ hora. Para as larvas de terceiro ínstar de Chrysomya regalis Robineau-Desvoidy (1830) Prins (1982) encontrou um comprimento de 14 a $18 \mathrm{~mm}$. O primeiro ínstar larval de $C$. chloropyga durou de 20 a $22 \mathrm{~h}$, e as larvas apresentaram em torno de $3,5 \mathrm{~mm}$ de comprimento, o período larval total durou de 162 a $230 \mathrm{~h}$, dependendo da disponibilidade do alimento; as larvas de terceiro ínstar removidas da dieta as $48 \mathrm{~h}$ tinham comprimento de 7,9 a 8,7 $\mathrm{mm}$; as removidas às $85 \mathrm{~h}$ tinham de $12 \mathrm{a} 13 \mathrm{~mm}$, e as larvas de final de terceiro ínstar de 16 a $17 \mathrm{~mm}$. A evolução das larvas por nós observada, a $27{ }^{\circ} \mathrm{C}$, demonstrou um tempo de 
Tabela II. Ritmo de crescimento de larvas de Chrysomya putoria (Wiedemann, 1818), criadas em carne bovina em início de decomposição e mantidas em câmara climatizada regulada a $27 \pm 1^{\circ} \mathrm{C}, 60 \pm 10 \%$ U.R. e fotofase de 14 horas.

\begin{tabular}{|c|c|c|c|}
\hline \multirow{2}{*}{$\begin{array}{l}\text { Período } \\
\text { (horas) }\end{array}$} & \multicolumn{3}{|c|}{ Tamanho $(\mathrm{mm})$} \\
\hline & Média & $\mathrm{DP}^{*}$ & IV95\%** \\
\hline 0 & 1,50 & 0,29 & $1,23-2,11$ \\
\hline 2 & 1,77 & 0,23 & $1,23-2,11$ \\
\hline 4 & 2,41 & 0,07 & $2,31-2,54$ \\
\hline 6 & 2,71 & 0,15 & $2,35-2,96$ \\
\hline 8 & 2,86 & 0,16 & $2,42-3,12$ \\
\hline 10 & 3,18 & 0,20 & $2,81-3,54$ \\
\hline 12 & 3,64 & 0,19 & $3,31-3,96$ \\
\hline 14 & 3,92 & 0,28 & $3,53-4,70$ \\
\hline 16 & 5,06 & 0,34 & $4,41-5,65$ \\
\hline 18 & 5,73 & 0,43 & $5,00-6,71$ \\
\hline 20 & 6,26 & 0,41 & $5,61-7,08$ \\
\hline 22 & 6,51 & 0,40 & $5,77-7,15$ \\
\hline 24 & 7,47 & 0,31 & $6,77-8,00$ \\
\hline 26 & 7,77 & 0,37 & $7,33-8,56$ \\
\hline 28 & 8,62 & 0,61 & $7,89-9,89$ \\
\hline 30 & 9,75 & 0,83 & $8,11-11,22$ \\
\hline 32 & 10,48 & 0,77 & $8,67-12,11$ \\
\hline 34 & 11,55 & 0,65 & $9,78-12,67$ \\
\hline 36 & 12,36 & 0,71 & $10,56-13,89$ \\
\hline 38 & 13,04 & 0,74 & $11,11-14,11$ \\
\hline 40 & 13,14 & 0,80 & $11,44-14,33$ \\
\hline 42 & 13,71 & 0,73 & $11,78-14,89$ \\
\hline 44 & 13,89 & 0,74 & $12,22-15,00$ \\
\hline 46 & 13,91 & 0,48 & $13,00-15,11$ \\
\hline 48 & 14,03 & 0,44 & $13,44-15,33$ \\
\hline 50 & 14,75 & 0,47 & $13,89-15,44$ \\
\hline 52 & 14,77 & 0,42 & $14,00-15,67$ \\
\hline 54 & 14,85 & 0,62 & $14,00-15,89$ \\
\hline 56 & 14,86 & 0,55 & $14,11-16,00$ \\
\hline 68 & 15,00 & 0,39 & $14,22-16,11$ \\
\hline 80 & 15,22 & 0,60 & $14,44-16,56$ \\
\hline 92 & 15,45 & 0,66 & $14,44-16,67$ \\
\hline
\end{tabular}

* DP - Desvio Padrão

** IV 95\% - Intervalo de Variação de 95\%

desenvolvimento e comprimento médio menor que as demais espécies do gênero.

Ishijima (1967) e Prins (1982) observaram em C. regalis a presença de esclerito oral acessório; a presença desse esclerito em forma de clava em Chrysomya pinguis (Walker, 1858) e pequeno em forma de vírgula em C. megacephala.

Segundo Erzinçlioglu (1989), o esqueleto cefalofaringeano de Phaenicia cuprina (Wiedemann, 1830) e Phaenicia sericata (Meigen, 1826) também apresenta o esclerito oral acessório, diferindo assim de C. putoria e Chrysomya albiceps (Wiedemann, 1819) que não apresentam essa estrutura. O mesmo autor também verificou que o esqueleto cefalofaringeano das duas últimas espécies é mais robusto e que serve como diferencial entre essas espécies. Queiroz et al. (1997) estudando aspectos morfológicos de larvas de $C$. albiceps, não observaram a presença do esclerito oral acessório. As larvas por nós analisadas não apresentaram o esclerito oral acessório, porém apresentaram o esqueleto cefalofaringeano robusto, corroborando as observações de Erzinçlioglu (1989).

Prins (1979) verificou que o gancho bucal de $C$. megacephala apresenta um aspecto largamente convexo, tendo a face basal superior um ângulo levemente arredondado; o gancho bucal de $C$. chloropyga apresenta a superfície dorsal ligeiramente plana, enquanto a posterior é achatada, ligeiramente côncava e com a face basal superior levemente elevada em ângulo mais agudo. Queiroz et al. (1997) descreveram o gancho bucal das larvas de terceiro ínstar de $C$. albiceps como sendo robusto, completamente pigmentado, curvo e denteado, a parte posterior é mais larga que a anterior, mostrando-se pontiaguda. Os caracteres encontrados para o gancho bucal neste trabalho assemelham-se aos descritos por Queiroz et al. (1997), mas em C. putoria não se apresenta denteado.

Queiroz et al. (1997) observaram ainda que o corno dorsal é de igual tamanho ao ventral e observaram uma região não pigmentada posteriormente em continuação aos cornos, sendo maior no corno dorsal. Neste trabalho, a região não pigmentada encontrava-se ligeiramente maior no corno ventral; em ambos foram verificadas porções dos cornos com menor pigmentação, contudo, essas porções são maiores em C. putoria.

Greenberg \& Szyka (1984) observaram que C. putoria apresenta espiráculo anterior com 10 a 12 ramificações; espiráculo posterior com peritrema incompleto e botão espiracular ausente. Esses resultados diferem dos encontrados neste trabalho, onde o espiráculo anterior apresentou de 10 a 11 ramificações e, observou-se a presença do botão espiracular a partir do segundo ínstar. Observando-se os trabalhos publicados com o gênero Chrysomya, leva-se a inferir que o botão espiracular não é uma característica desse gênero com exceção, segundo James (1947), de Chrysomya bezziana (Villeneuve, 1914) que apresenta o botão espiracular. Queiroz et al. (1997) observaram que C. albiceps apresenta de 10 a 12 ramificações; peritrema robusto e incompleto com duas estruturas proeminentes entre as aberturas espiraculares, semelhantes às encontradas neste experimento em C. putoria, que os autores acreditam ser de sustentação e, ausência de botão espiracular. $\mathrm{O}$ número de estruturas proeminentes observadas neste trabalho varia de acordo com o ínstar, encontrando-se entre as aberturas espiraculares; peritrema aberto.

James (1947) descreveu alguns aspectos de larvas do gênero Chrysomya; observou que o espiráculo anterior de $C$. chloropyga apresenta de 10 a 11 ramificações, o posterior com peritrema incompleto, ausência do botão espiracular e tamanho médio das larvas maduras de 12mm; para Chrysomya marginalis (Wiedemann, 1830) o espiráculo anterior apresentava 12 ramificações e o posterior com peritrema incompleto, ausência do botão espiracular e comprimento entre 12 a 14 mm para as larvas de terceiro ínstar. James (1947) verificou a presença de botão espiracular em $C$. bezziana, o peritrema dos espiráculos posteriores incompleto, o espiráculo anterior apresentava de quatro a cinco ramificações e comprimento larval de 14 a $18 \mathrm{~mm}$ para o terceiro ínstar. Nossos 
estudos demonstraram diferenças entre C. putoria e as espécies descritas por James (1947); a presença do botão espiracular a difere de $C$. chloropyga e $C$. marginalis e, o número de ramificações (10 a 11) e seu tamanho médio (13,3 mm) a diferem de C. bezziana.

\section{REFERÊNCIAS}

Erzinçlioglu, Y. Z. 1989. The early larval ínstars of Lucilia sericata and Lucillia cuprina (Diptera, Calliphoridae): myiasis blowflies of Africa and Australia. Journal of Natural History 23: 1133-1136.

Furlanetto, S. M. P.; Campos, M. L. C.; Hársi, C. M.; Buralli, G. M. \& Ishihata, G. K. 1984. Microorganismos enteropatogênicos em moscas africanas pertencentes ao gênero Chrysomya (Diptera, Calliphoridae) no Brasil. Revista de Microbiologia 15: 170174.

Greenberg, B. 1971. Flies and disease, vol. 1. Ecology, classification and biotic association. Princeton University Press, Princeton, NJ. $856 \mathrm{pp}$.

Greenberg, B. 1973. Flies and disease, vol. 2. Biology and disease transmission. Princeton University Press, Princeton, NJ.

Greenberg, B. \& Szyska, M. L. 1984. Immature stages and biology of fifteen species of Peruvian Calliphoridae (Diptera). Annals of the Entomological Society of America 77: 48-517.

Ishijima, H. 1967. Revision of the third stage larvae of synantropic flies of Japan (Diptera: Anthomyidae, Muscidae, Calliphoridae and
Sarcophagidae). Japanese Journal of Sanitary Zoology 18 : 47-100.

James, M. T. 1947. The flies that cause myiasis in man. United States Department of Agriculture. Washington, D.C. 175 p.

Lopes, H. S. 1943. Contribuição ao conhecimento das larvas dos Sarcophagidae com especial referência ao esqueleto cefálico (Diptera). Memórias do Instituto Oswaldo Cruz 38: 127163.

Lopes, H. S. 1982. The importance of the mandible and clypeal arch of the first ínstar larvae in the classification of the Sacophagidae (Diptera). Revista Brasileira de Entomologia 26: 293-326.

Mariluis, J. C. 1999. Notas sobre moscas metalizadas, su importancia sanitaria y ecología (Diptera: Calliphoridae). Revista de la Sociedad Entomológica Argentina 58: 289-294.

Mcalpine, J. F.; Peterson, B. V.; Shewell, G. E.; Teskey, J. H.; Vockeroth, J. R. \& Wood, D. N. 1981. Manual of Neartic Diptera. Monograph 1: $674 \mathrm{p}$.

Prins, A. J. 1979. Discovery of the oriental latrine fly Chrysomya megacephala (Fabricius) along the south western coast of South Africa. Annals South African Museum 78: 39-47.

Prins, A. J. 1982. Morphological and biological notes on six South African blow-flies (Diptera, Calliphoridae) and their immature stages. Annals South African Museum 90: 201-217.

Queiroz, M. M. C., Mello, R. P. \& Lima, M. M. 1997. Morphological aspects of the larval ínstars of Chrysomya albiceps (Diptera, Calliphoridae) reared in the laboratory. Memórias do Instituto Oswaldo Cruz 92: 187-196.

Zumpt, F. 1965. Myiasis in man and animals in the old world. Butterworths, London. 267 p. 